\title{
Desde y por la genealogía de mujeres intelectuales. Una entrevista a la editora de La Hoguera, Joyce Contreras
}

\author{
Towards a Genealogy of Women Intellectuals. \\ An Interview With Joyce Contreras \\ Claudia Montero \\ Universidad de Valparaíso, Chile \\ http://orcid.org/0000-0001-5209-0931 \\ claudia.montero@uv.cl
}

La Hoguera Editora es un sello editorial que lanzó su primer título en 2020 en Chile, en medio de la crisis de la pandemia y tras la revuelta social. No podría haber tenido otro nombre que este, siendo su creadora Joyce Contreras Villalobos ${ }^{1}$ (Santiago, 1987), investigadora experta en la escritura de mujeres y feministas del siglo XIX.

La Hoguera hace eco de las experiencias de las intelectuales latinoamericanas que, excluidas del espacio público por su condición genérico-sexual, fueron discriminadas y violentadas por cruzar los límites de lo doméstico, y cuyas editoriales fueron quemadas no una vez, sino varias, como fue el caso de la peruana Clorinda Matto de Turner. Tampoco podemos dejar de pensar en el Mayo Feminista de 2018, que salió con

1 Profesora de Lengua Castellana, licenciada en Lengua y Literatura Hispánica por la Universidad de Chile y doctora en Literatura por la Pontificia Universidad Católica de Valparaíso. 
fuerza a demandar el fin de la violencia machista y quemarlo todo para refundar una sociedad respetuosa de todes. Y, finalmente, no podemos dejar de ver en el logo de La Hoguera Editora una imagen que nos lleva al octubre chileno de 2019, que marcó el inicio de un proceso de cambio social.

La Hoguera Editora es un proyecto esperado y no sorprende que sea Joyce Contreras quien lo haya creado. Ella es una investigadora inquieta que, en su compromiso por estudiar a sujetos y producciones escriturales marginadas del canon académico, ha pesquisado la literatura de cordel, las narrativas desde y sobre los márgenes, y sobre todo la escritura de mujeres decimonónicas. Su empuje y convicción la llevó a publicar tempranamente en su carrera académica el libro Mercedes Marín del Solar (1804-1866). Obras reunidas (Centro de Investigaciones Diego Barros Arana, 2015). Lo que ha venido después es solo muestra de su rigurosidad y capacidad productiva: fue coautora del volumen de ensayos Escritoras chilenas del siglo XIX. Su incursión pionera en la esfera pública y el campo cultural (RIL Editores, 2017) y de Las musas se emancipan. Antología de ensayo de género en Chile (1870-1940), que prontamente saldrá a la venta por el sello editorial Cuarto Propio. Todo esto apoyada por proyectos de financiamiento público académico como Fondecyt y el Fondo del Libro del Ministerio de las Culturas, las Artes y el Patrimonio.

La Hoguera Editora es un esfuerzo por cruzar los límites del mundo académico para divulgar cuestiones fundamentales para pensar nuestra sociedad actual, como lo es el pensamiento feminista. Responde a los olvidos del archivo, que ha invisibilizado las producciones de mujeres y disidencias, y también a las necesidades investigativas en el contexto de la pandemia. Este esfuerzo se realiza a pulso e individualmente, en una labor encomiable y responsable, acompańada de un club de lectura donde revisan a las autoras que forman parte del catálogo de La Hoguera y de otras intelectuales del siglo XIX.

CLAUDIA MONTERO (CM): ¿Cómo se relaciona tu trayectoria vital, laboral, académica con la fundación de La Hoguera Editora?

JOYCE CONTRERAS (JC): La creación de La Hoguera Editora fue un proyecto que surgió, como muchos, sin haberlo premeditado. Sus inicios se remontan a un proyecto de investigación postdoctoral Fondecyt que desde el año 2018 llevo a cabo en la Facultad de Filosofía y Humanidades de la Universidad de Chile, el cual trata sobre el ensayo de género 
escrito por autoras chilenas entre 1870 y 1940. En ese contexto, hace un par de años di en un archivo con el que fue el primer libro de ensayos escrito por una autora en Chile: se trata de Mis observaciones de Delie Rouge (seudónimo de la escritora Delia Rojas) publicado originalmente en 1915. Este texto, fuera de desconocido, ni siquiera estaba disponible en la Biblioteca Nacional. Luego de fotografiarlo y estudiar los siete ensayos que lo componen, comencé a reconstruir la vida la autora y me sorprendí enormemente al descubrir su participación en organizaciones y publicaciones periódicas feministas de principios de siglo XX. Sin ir más lejos, fue una de las primeras militantes del Movimiento Pro-Emancipación de las Mujeres de Chile (MEMCH). A partir de ese proceso de investigación nació la idea de reeditar el libro con un breve prólogo que pusiera en diálogo a la autora con su contexto de producción. Como no quería pasar por la experiencia cansadora de ofrecer este proyecto a sellos editoriales, ni postularlo a fondos concursables, decidí armar La Hoguera en agosto de 2020. De esta manera, la editorial surge vinculada a mi interés, por un lado, por estudiar la historia de la literatura escrita por mujeres y los feminismos en Chile, y por otro, por difundir entre los y las lectoras estos textos pioneros que muchas veces solo quedan en manos de los y las investigadores.

CM: ¿Cuál es el objetivo de la editorial?

JC: Hoguera nace con el fin de rescatar, visibilizar y poner en valor a autoras tradicionalmente excluidas, ya sea del canon académico o bien del mercado editorial. Esta marginación obedeció, muchas veces, a su condición genérico-sexual, pues sabemos de los múltiples obstáculos que encontraron las mujeres que querían escribir o publicar, sobre todo durante el siglo XIX y principios del XX. No obstante, también hay otro muy punto relevante, que es el carácter incendiario o a contracorriente de sus ideas, de allí el nombre del sello, que alude a la quema de libros, a la censura, así como también a la caza de brujas. El énfasis de La Hoguera está puesto, de este modo, en el cruce entre archivos, literaturas y feminismos, en particular, latinoamericanos. El propósito es llegar, a través de una voluntad divulgativa, aunque no por ello menos rigurosa, a un público lector amplio, interesado/a en conocer a escritoras que, a contrapelo de su época, asumieron posturas críticas y defendieron ideas de avanzada, además de hacer aportes relevantes a la cultura. Estas escrituras, vistas desde el siglo XXI, resultan hoy de máxima actualidad. 
CM: Entrando a una cuestión más compleja, ¿cómo te asumes como editora y en ese sentido cómo La Hoguera Editora da cuenta de ese lugar?

JC: Crear un sello editorial es una experiencia súper enriquecedora, creativa y estimulante, pues implica la decisión de publicar a autoras y obras que a una como lectora le encantaría poder encontrar en una librería y que, no obstante, la mayoría de las veces no se encuentran. Sin embargo, de igual forma constituye una tarea titánica, ya que no solo implica muchísimo trabajo, sino que también representa todo un reto en términos económicos, lo cual pone en cuestión la tradicional imagen romántica asociada a la figura del editor como aquel sujeto que revisa manuscritos acompañado de un café (imagen que, en efecto, forma solo una "parte" de un largo proceso). En mi opinión, es fundamental, si se quiere construir y consolidar un sello editorial, que este se vuelva autosustentable económicamente, evitando depender de forma exclusiva de los fondos concursables, los que, sabemos, son muy fluctuantes. En este sentido, saber elegir qué publicar, considerando su novedad y potencial impacto en el mercado editorial, es un elemento clave.

Complementando lo anterior, ahora como editora feminista pienso y dimensiono el tremendo esfuerzo que realizaron una serie de escritoras, muchos años atrás, quienes igualmente se arrojaron a la tarea de editar, ya sea un medio (como Rosario Orrego, Clorinda Matto o Ana Roqué, con sus respectivos periódicos), un sello editorial (como lo hizo, con sus condiciones de privilegio, Victoria Ocampo), o bien, que decidieron autopublicarse (como Winétt de Rokha). En mi caso, coincide que las autoras con las que trabajo igualmente tuvieron una relación, más o menos tensa, con el mundo de la edición. En ese sentido, procuro, a través de los prólogos que acompañan a las reediciones, dar cuenta de ese rol agente que desarrollaron ellas.

CM: ¿Cuáles son los títulos de tu catálogo?

JC: Los dos títulos que hasta el momento conforman el catálogo de La Hoguera forman parte de la colección de ensayo llamada "Obreras del pensamiento". Por un lado está Mis observaciones de Delie Rouge, reedición del primer libro de ensayos escrito por una autora en Chile en 1915, el cual va a acompańado de un prólogo que pone en diálogo a la autora con su contexto de producción, visibilizando las múltiples dificultades que ella tuvo que sortear para insertarse en el excluyente campo cultural de inicios del siglo XX en Chile. El próximo libro, que 
está por publicarse en agosto, se trata de la reedición del libro de ensayos Mi opinión. Sobre las libertades de la mujer como compañera, madre y ser independiente, publicado en 1913 por la feminista, anarquista y sindicalista puertorriqueña Luisa Capetillo. Este va prologado por la académica Lucía Stecher. En relación con los títulos venideros, estos van en la misma línea: un rescate de obras ensayísticas escritas por autoras latinoamericanas, pioneras de los feminismos, de mediados del siglo XIX y principios del XX.

CM: ¿Qué complejidades tiene reeditar escrituras de mujeres del siglo XIX y el temprano siglo XX latinoamericano?

JC: En primer lugar, me atrevería a decir que el acceso a los libros originales constituye hoy una gran dificultad, dado el prolongado cierre de archivos y bibliotecas que, desde principios del año 2020, debido a la situación sanitaria generada por el COVID-19, nos ha impedido a las y los investigadores a ir en búsqueda de estos títulos, en su mayoría muy antiguos y de acceso limitado, en algunos casos. La mayoría de estos, evidentemente, tampoco están disponibles para su compra ni se encuentran digitalizados. En segundo lugar, creo que otro problema tiene que ver con la obtención de derechos de autor. Hay que mencionar que, al menos en Chile (y tengo entendido que esta situación se replica en otros países de América Latina), no existe una base datos en donde se pueda identificar y contactar a los o las herederas de los derechos de autor de esta/os escritora/es. Ello hace complejo, por ejemplo, querer reeditar algún texto, ya que cuando aún no han transcurrido setenta ańos desde el fallecimiento de un/a autor/a, si no hay un contrato explícito de cesión de derechos (lo que implica muchas veces un pago por este concepto, aspecto que se torna difícil para las microeditoriales y/o editoriales independientes cuyos recursos son limitados), estas obras todavía no quedan liberadas de derechos, por lo que resulta imposible reeditarlas. Ello frena algunas veces la voluntad del editor de rescatar y poner nuevamente en circulación a dichos autores y sus obras.

CM: ¿Cuáles son los temas que abordan las autoras que rescatas?

JC: Los temas que estas escritoras abordan resultan, como he dicho, de una actualidad que hoy nos sorprende debido a la vigencia de las inquietudes e ideas planteadas. En este sentido, las autoras, durante la temprana década de 1910, hablan acerca de temáticas absolutamente a contracorriente de su época, como la necesidad de abolir la institución 
del matrimonio, la libertad sexual para hombres y, en especial, para las mujeres; la necesidad de educación para la mujer y su independencia económica, la defensa de la mujer prostituta, a la que se considera una víctima del sistema; la urgencia de una ley de divorcio (que en el caso de Chile, se materializó insólitamente solo casi cien años después, en 2004); la crítica contra instituciones poderosas en aquella época, como la Iglesia católica, el Estado y el patriarcado; la hipocresía social, el abandono de parte del Estado de los niños pobres y/o huérfanos, el peligroso avance de las ideologías conservadoras, entre otras. Todas temáticas y problemas que aún hoy nos interpelan.

CM: En relación con el tema de los derechos políticos, ¿cómo ves la relación de estas autoras con el sufragismo?

JC: Autoras como Delie Rouge, que si bien no abarca en sus ensayos tempranos -reunidos en Mis observaciones (1915)- la demanda sufragista, durante la década de 1920 y 1930 se va a unir como colaborada a otras publicaciones periódicas feministas como Acción Femenina, órgano del Partido Cívico Femenino (1922), cuyo objetivo era luchar por la obtención de reformas legales que pusieran fin a la situación de subordinación en que vivían las mujeres. En este sentido, el sufragio femenino universal fue una de las banderas de lucha de la publicación. En la década de 1930, Delie se unirá a las militantes del MEMCH, organización política feminista de izquierda, en la que también se exigirá la obtención del derecho al sufragio femenino, entre otras prerrogativas. Allí ella ejercerá como Secretaria de Prensa de dicha organización y también participará como colaboradora en su órgano oficial, La Mujer Nueva, donde reclamará el mejoramiento de las condiciones de vida de las mujeres obreras. De esto podemos deducir que ella mantiene una estrecha cercanía política a las instituciones feministas que por esos años están exigiendo el derecho de sufragio.

En el caso de Luisa Capetillo, es posible ver cómo la demanda por el sufragio femenino va a constituirse en uno de sus varios motivos de lucha. Por ejemplo, mientras se desempeñaba como sindicalista en 1908 en la Federación Libre de Trabajadores de Puerto Rico, utilizó esta tribuna para exigir, entre otros, el derecho a voto para las mujeres. También se refiere a la necesidad de este derecho en el libro Mi opinión de 1913. En este, legitimará el tan criticado actuar radicalizado de las suffragettes: “iLa libertad de la mujer, es la libertad del género humano!... 
¡Con cuánta razón destruyen las sufragistas en Londres lo que solamente es de los hombres y por los hombres! ¡Abajo la civilización hecha con la esclavitud de las mujeres!".

CM: ¿Cómo aporta el trabajo de La Hoguera Editora a la discusión actual y construcción del feminismo contemporáneo?

JC: Me parece que es importante el trabajo de rescate que realiza La Hoguera, en el sentido de escarbar en los archivos y dar con estas autoras y textos que de alguna manera contribuyeron a pavimentar el camino, no solo para el posterior ingreso de las escritoras a los campos literarios y culturales de la región, sino también para abrir y ensanchar la senda de los movimientos feministas en América Latina. Y hablo en plural, porque tal como ahora se habla de los diferentes feminismos que coexisten, hace un siglo atrás acontecía algo bastante similar. Tenemos a escritoras y militantes feministas provenientes de diferentes clases sociales: populares, medias, y ya no exclusivamente de la élite, como ocurrió durante gran parte del siglo XIX. Estas autoras van a reivindicar en sus textos la necesidad de entender la emancipación de la mujer atendiendo igualmente a otros factores como la clase social. En este sentido, es notable su interés por el mejoramiento de las condiciones de vida de las mujeres trabajadoras y obreras. Me parece que estas reflexiones se conectan con un concepto muy propio del feminismo contemporáneo que tiene que ver con la interseccionalidad, vale decir, con comprender que la opresión de género constituye una variable que interactúa con otras como la clase, la raza y la identidad sexual, en un contexto histórico particular. Estas escritoras, muy adelantadas a su época, de cierta forma ya tenían conciencia de que no todas las mujeres somos iguales, y de que algunas que sufrían mayor opresión que otras. Una discusión muy vigente hoy. 